\title{
PENERAPAN MODEL PEMBELAJARAN CATUR PARIKSA DIPADUKAN DENGAN DISKUSI UNTUK MENINGKATKAN AKTIVITAS DAN PRESTASI BELAJAR
}

\author{
Oleh \\ I Nengah Dwi Endra Suanthara \\ Ni Made Ayu Arini \\ STKIP Agama Hindu Singaraja, Singaraja Indonesia \\ Email: dwisuanthara@gmail.com
}

\begin{abstract}
ABSTRAK
Tujuan penelitian ini adalah untuk meningkatkan aktivitas dan prestasi belajar pendidikan Agama Hindu siswa kelas XI IPB 4 SMA Karya Wisata Singaraja. Penelitian ini dilaksanakan dalam dua siklus dengan empat tahapan meliputi: perencanaan, pelaksanaan, observasi/evaluasi dan refleksi. Subjek penelitian ini adalah siswa kelas XI IPB 4 SMA Karya Wisata Singaraja berjumlah 33 orang terdiri dari 17 siswa laki-laki dan 16 perempuan. Metode pengumpulan yang digunakan: observasi, wawancara, dan tes prestasi belajar. Analisis data yang digunakanadalah deskriptif-kualitatif. Berdasarkan hasil analisis ditemukan bahwa terdapat peningkatan aktivitas belajar siswa pada siklus I sebesar $37 \%$ meningkat pada siklus II menjadi $84 \%$, demikian juga halnya pada prestasi belajar siswa terdapat peningakatan pada siklus Iditemukan; rata-rata kelas (Mean) sebesar 73.70, daya serap (DS) sebesar 73,70\%, dan ketuntasan belajar (KB) sebesar 56\%, meningkat pada siklus II menjadi ratarata kelas (Mean) sebesar 84,44, daya serap (DS) sebesar 84,44\%, dan ketuntasan belajar sebesar $100 \%$. Hasil tersebut sudah melampaui dari target yang diharapkan yaitu target rata-rata kelas (M) sebesar 80, daya serap siswa (DS) sebesar 80\% dan ketuntasan belajarnya $(\mathrm{KB})$ sebesar $80 \%$. Keberhasilan penelitian ini disebabkan oleh faktor penerapan model pembelajaran guru telah dilahsanakan dengan tepat dan benar sesuai setandar oprasional prosedur yang telah disusun. Direkomendasikan kepada para guru khususnya guru Agama Hindu untuk dapat menggunakan model pembelajaran ini untuk meningkatkan proses dan mutu luaran.
\end{abstract}

Kata Kunci: Catur Pariksa, Diskusi, Aktivitas, Prestasi Belajar.

\begin{abstract}
The purpose of this study was to increase the activity and academic achievement of Hindu Religion students in class XI IPB 4 SMA Karya Wisata Singaraja. This research was conducted in two cycles with four stages including: planning, implementation, observation / evaluation and reflection. The subjects of this study were 33 students in class XI IPB 4, Karya Wisata Singaraja, consisting of 17 male and 16 female students. Collection methods used: observation, interviews, and learning achievement tests. Analysis of the data used is descriptive-qualitative. Based on the results of the analysis it was found that there was an increase in
\end{abstract}


ISSN: 2656-7466

student learning activities in the first cycle by $37 \%$, increasing in the second cycle to $84 \%$, as well as the students' learning achievement there was an increase in the first cycle; average class (Mean) of 73.70, absorptive capacity (DS) of 73.70\%, and mastery learning $(\mathrm{KB})$ by $56 \%$, increased in the second cycle: a class average (Mean) of 84.44 , absorption (DS) of $84.44 \%$, and mastery learning by $100 \%$. These results have exceeded the expected target of an average class target (M) of 80, student absorption (DS) of $80 \%$ and mastery learning (KB) of $80 \%$. The success of this research was due to the fact that the application of the teacher learning model has been carried out appropriately and correctly according to standard operational procedures that have been prepared. It is recommended that teachers especially Hindu Religion teachers can use this learning model to improve the process and quality of outcomes.

\section{Keywords: Catur Pariksa, Discussion, Activities, Learning Achievement.}

\section{PENDAHULUAN}

Dewasa ini, pendidikan menjadi sorotan penting di masyarakat karena pendidikan merupakan salah satu cara untuk meningkatkan kualitas sumber daya manusia agar dapat bersaing pada era globalisasi. Pendidikan merupakan pilar dalam tegaknya suatu bangsa. Melalui pendidikan bangsa akan mampu menjaga martabat. Kualitas sumberdaya manusia sangat menentukan perkembangan suatu bangsa, keberhasilan dalam menghadapi persaingan global juga ditentukan oleh mutu kemampuan sumber daya manusia. Penciptaan sumber daya manusia yang berkualitas dan memiliki daya saing perlu didukung oleh sistem pendidikan yang baik. Sesuai dengan tujuan Pendidikan Nasional Indonesia, salah satu tujuan utama sekolah adalah membentuk dan mengembangkan kepribadian anak. Upaya itu pada dasarnya mencakup hal umum yakni: perkembangan kemampuan kognitif dan keterampilan serta pengembangan watak dan akhlak moral agar kelak menjadi manusia yang religious, berilmu dan bertanggung jawab,sejalan dengan Undang- Undang Pendidikan Nasional No. 20/2003 yaitu bertujuan untuk berkembangnya potensi peserta didik agar menjadi manusia yang beriman, bertakwa pada Tuhan Yang Maha Esa, berakhlak mulia, berilmu, sehat, cakap, kreatif, mandiri dan menjadi warga Negara yang demokratis serta bertanggung jawab. Proses pengembangan kemampuan dan kepribadian itu dapat dilakukan melalui interaksi proses pembelajaran di kelas, menciptakan pembelajaran yang kondusif, maupun melalui kepribadian guru yang dalam hal ini sebagai teladan yang berkarakter berkepribadian yang baik. Peranan guru Agama Hindu kini sangat ikut berperan membangun anak didik sedini mengkin dan ikut bertanggung jawab 
membangun dasar manusia yang beriman yang kuat melalui pendidikan, baik di sekolah maupun di lingkungan masyarakat, menjadi panutan dan pembimbing yang aktif serta kreatif di segala bidang sesuai profesi yang dimilikinya, pada umat Hindu yang memerlukan penyuluhan rohani agar memperoleh pembinaan yang sesuai dengan ajaran agama Hindu untuk meningkatkan keimanannya. Pendidikan agama yang sesuai dengan kaidah dan sastra yang benar akan dapat melahirkan luaran yang beriman dengan memiliki moralitas yang tinggi, produktif, efisien, dan efektif dalam mengemban tugastugas bangsa serta mampu berkompetitif atau bersaing secara sehat dengan warga disekitarnya. Berdasarkan hasil observasi fenomena yang muncul di kelas XI IPB 4 SMA Karya Wisata Singaraja terkait aktivitas pendidikan Agama Hindu rendah seperti; siswa kurang memahami pelajaran karena siswa tidak memperhatikan penjelasan guru dan bermain dalam kelas, 2) kurangnya minat belajar siswa disebabkan cara mengajar guru membosankan dan memakai metode ceramah saja,

3) siswa malu bertanya/ mengemukakan pendapatnya saat proses pembelajaran karena tidak memiliki kepercayaan diri dan kurangnya daya kreativitas guru dalam memotivasi siswa untuk berpendapat, 4) kurangnya daya serap siswa terhadap materi bahkan suka tidur setiap jam pelajaran sebab siswa pasif, hanya duduk diam mendengarkan penjelasan guru, 5) kurangnya keinginan siswa untuk mengetahui tentang materi yang berkaitan dengan bidang studi Agama Hindu, siswa merasa bahwa pelajaran tersebut tidak terlalu penting. Disamping itu, dari hasil pretest menunjukkan bahwa prestasi belajar siswa masih rendah dimana, rata-rata kelas $=61,08$ sedangkan daya serap hanya mencapai $61,08 \%$ dan ketuntasan belajar hanya 33\% dari 36 siswa. Faktor penyebab rendahnya prestasi siswa antara lain factor guru dalam proses pembelajaran masih menggunakan metode konvensiona, factor siswa kurang mengerti terhadap materi yang di sampaikan guru, siswa pasif, kurangnya perhatian siswa pada materi kurangnya kesadaran untuk belajar mandiri, kurangnya keterlibatan siswa dalam aktivitas belajar. Ada beberapa alternatif yang bisa digunakan untuk memecahkan masalah tersebut yaitu: model inquiry learning, cooprativelearning, model pembelajaran consep catur pariksa dipadukan dengan diskusi. Dari beberapa alternatif pemecahan masalah seperti yang disebutkan di atas, peneliti menggunakan alternatif yang ketiga, yaitu penerapan model pembelajaran Catur Pariksa yang dipadukan dengan diskusi karena dengan menerapkan model pembelajaran ini dapat menjadikan siswa lebih aktif, kreatif, termotivasi atau siswa memiliki motivasi untuk berinteraksi dengan 
siswa yang lain maupun dengan guru. Tujuan penelitian adalah untuk mengkaji pembelajaran catur pariksa dipadukan dengan diskusi dapat meningkatkan aktivitas dan prestasi belajar siswa. Ada beberapa teori yang digunakan untuk memperkuat pemecahan masalah dalam penelitian ini terdiri dari: 1) teori pembelajaran humanistik yang mendukung model pembelajaran Catur Pariksa (sama, bedha, dhana, dan dhanda), yang memuat indikator pembelajaran ekuivalen dengan pembelajaran humanistik yang menekankan pada pengembangan potensi diri siswa, 2) belajar trial and eror, 3) pemberian reward, 4) pemberian punishment atau hukuman. Disamping itu juga menggunakan teori belajar diskusi, aktivitas belajar dan teori prestasi belajar.

\section{METODE PENELITIAN}

Metode penelitian yang digunakan penelitian tindakan kelas (PTK) terdiri dari empat tahap yaitu, perencanaan (plaining), pelaksanaan (action), (observasi, evaluasi dan analisis data) serta refleksi. Dalam perencanaan tindakan ini sebelum melaksanakan kegiatan lebih lanjut hal yang perlu diperhatikan adalah partisipasi dari semua pihak yang terlibat dalam penelitian ini serta kesediaan fasilitas yang akan digunakan. Pelaksanaan tindakan dilaksanakan sesuai jadwal pelajaran yaitu satu kali tatap muka selama 135 menit. Metode pengumpulan data digunakan observasi dan testing. Analisis data adalah deskriptif kualitatif, karena yang diinginkan adalah bagaimana cara guru untuk meningkatkan aktivitas dan prestasi belajar siswa. Subyek yang diteliti adalah siswa kelas XI IPB 4 SMA Karya Wisata Singaraja sebanyak 36 orang siswa terdiri dari laki-laki 23 orang dan perempuan 13 orang perempuan.

\section{HASIL PENELITIAN DAN PEMBAHASAN}

Hasil penelitian pendahuluan ditemukan bahwa aktivitas belajar siswa masih rendah sebagian besar siswa kurang memperhatikan guru dalam menyampaikan materi pelajaran, kerjasama dalam memecahkan masalah kurang, sebagian besar siswa tidak mau bertanya atau pun menjawab pertanyaan guru, kurang inisiatif untuk berpendapat. Dari hasil pretest ditemukan prestasi belajar siswa masih rendah yaitu: rata-rata kelas sebesar (M) 61,08, daya serap (DS) 61,08\% dan ketuntasan belajarnya (KB) 33\%. Pada siklus I (satu) hasil treatment diperoleh: aktivitas belajar siswa 37\%, rata-rata kelas sebesar 73,70, daya serap sebesar 73,70\%,dan ketuntasan belajar sebesar $56 \%$. Berdasarkan data ini target penelitian belum tercapai. Dilihat dari hasil refleksi awal kelas Nampak sudah ada peningkatan namun belum signifikan. Dari hasil observasi 
ditemukan ada beberapa faktor yang masih belumefektif member kontribusi terhadap proses pembelajaran yaitu: factor guru; guru belum maksimal menerapkan indicator pembelajaran catur pariksa, implementasi teori humanistic belum terlaksana dengan baik sehingga potensi siswa tidak nampak, pembelajaran trial and errol belum kelihatan dilaksanakan oleh guru, penerapan reinforcement masih belum maksimal. Factor siswa; suasna kelas masih pasif, siswa tidak kreatif, nampak ada rasa ragu-ragu, kurang termotivasi untuk mencoba, bertanya, berpendapat. Keputusan akhir siklus I (satu) adalah melanjutkan treatment pada siklus II (dua). Pada siklu dua guru memusatkan treatment pada factor yang lemah pada siklus sebelumnya dengan tidak mengabaikan faktor yang sudah berkembang dengan baik. Hasil yang diperoleh pada siklus II (dua) adalah aktivitas belajar siswa meningkat secara signifikan dari $37 \%$ pada siklus I menjadi $84 \%$ pada siklus II, rata-rata prestasi belajar sebesar 84,44 , daya serap sebesar $84,44 \%$ dan ketuntasan belajar sebesar $100 \%$. Hasil penelitian pada siklus II sudah melebihi target penelitian sehingga penelitian ini dinyatakan berhasil. Peningkatan hasil penelitian yang dinyatakan pada siklus II mempunyai hubungan yang linier antara faktor guru sebagai pengajar, terhadap proses belajar dan hasil/prestasi belajar siswa. Guru telah berhasil dengan baik dalam menerapkan model pembelajaran catur pariksa dan diskusi sesuai dengan setandar oprasional prosedur yang tertuang dalam rencana pembelajaran. Indkkator pembelajaran semuanya diterapkan dengan sistematis dan benar hal ini disebut stumulus (S). Stimulus (S) ini memunculkan respon (R) siswa yang sangat variatif dari hasil observasi diperoleh: 1) perhatian siswa terpusat kepada materi yang disampaikan oleh guru dengan respon sebesar $88 \%$ hanya $12 \%$ masih ada yang kurang focus, 2) kerjasama dalam memecahkan masalah pelajaran respon siswa sebesar $83 \%$ berarti $17 \%$ siswa yang kurang aktif (beberapa yang diam, beberapa berpendapat tapi ragu-ragu, ada juga yang hanya menulis untuk dirinya), 3) aktivitas menulis/mencatat materi yang dijelaskan guru direspon $88 \%$,4) aktivitas mempresentasikan hasil diskusi respon siswa sebesar $80 \%$. Presentasi kelompok membutuhkan kerjasama mental atau psikhis. Peranserta siswa dalam member jawabanatas pertanyaan menjadi objek penilaian. 5) aktivitas menanggapi pertanyaan dari teman dan guru respon siswa sebesar $83 \%$ masih ada $17 \%$ siswa yang kurang aktif hal ini disebabkan waktu yang disediakan untuk proses Tanya jawab ini sangat sedikit sehingga cenderung diwakili oleh temannya yang suka bicara atau yang lebih memahami masalah yang dibahas. Keberhasilan peneliti di atas dipengaruhi oleh terciptanya proses pembelajaran yang kondusif, dimana 
siswa merasa tertantang dan bertanggungjawab terhadap tugas yang diberikan oleh guru dan merasa senang dalam proses pembelajaran baik secara individu maupun kelompok. Temuan ini sejalan dengan teori humanistik bahwa belajar adalah proses memanusiakan manusia itu sendiri. Temuan ini juga didukung teori Athur combs (dalam Ratna Wilis Dahar, 1989:12) dinyatakan bahwa belajar merupakan proses pengembangan potensi diri siswa dalam proses pembelajaran. Siswa mampu dan berani menjawab pertanyaan yang diberikan oleh guru atau siswa lain tanpa merasa takut dan malu jika salah menjawab pertanyaan. Hal ini sesuai dengan Teori trial and eror (Thorndike, 1984) yang menyatakan pemberian stimulus secara bertingkat akan meningkatkan motivasi siswa dalam memberikan respon meskipun mengalami kegagalan dan kegagalan menjadikan mereka berhasil. Proses belajar yang menekankan pada belajar siswa aktif dapat menumbuh kembangkan perkembangan mental belajar dan aktivitas fisik. Proses tersebut mengakibatkan daya tangkap dan daya ingat siswa menjadi tahan lama. Proses ini terbentuk melalui penerapan teori reinforcement yang diterapkan dengan tepat dan benar. Setiap respon siswa dihargai oleh guru sesuai dengan kondisi respon tersebut. Penghargaan repon siswa berdampak pada tumbuhnya keinginan/keberanian siswa untuk mencoba menjawab pertanyaan, berpendapat. Lama kelamaan keberanian berpendapat menjadi kebiasaan. Jika proses penerimaan pengetahuan sudah menjadi kebiasaan maka pengetahuan itu tersimpan dalam memori yang dalam sehingga bisa bertahan lama. Pengetahuan yang dimiliki siswa kemudian diterapkan dalam kehidupan sehari-hari maka menjadi permanen atau tidak terlupakan. Dalam praktek pembelajaran siswa yang pemahaman pembelajarannya ketika dalam proses belajar bagus akan terealisasikan dalam bentuk prestasi belajar. Hal ini terbukti bahwa keberhasilan proses belajar siswa ditunjukkan dengan prestasi belajar. Pada siklus II sangat jelas kelihatan bahwa prestasi belajar siswa meningkat signifikan.

Tabel 1. Prestasi Belajar Sisiwa

\begin{tabular}{lcccc}
\hline Aspek & Siklus I & Siklus II & Target & \multicolumn{2}{c}{ Ket } \\
\hline Mean & 73,70 & 84.44 & 80 & Berhasil \\
Daya Serap & $73,70 \%$ & $84.44 \%$ & $80 \%$ & Berhasil \\
Ketuntasan Belajar & $56 \%$ & $100 \%$ & $80 \%$ & Berhasil \\
\hline
\end{tabular}


Tabel di atas menunjukkan bahwa aktivitas pembelajaran yang meningkat dapat menyebabkan pemahaman siswa meningkat, artinya siswa lebih mudah mengerti materi pelajaran yang disampaikan oleh guru. Dalam tabel di atas ditunjukkan dengan daya serap terhadap materi pelajaran adalah $100 \%$. Artinya guru dapat menyelesaikan semua rencana pembelajarannya dan siswa mampu memahami dengan baik. Jadi model pembelajaran catur pariksa dan diskusi yang diterapkan dengan baik dan benar sebagai faktor utama peningkatan aktivitas dan prestasi belajar siswa dalam pelajaran Agama Hindu dan Budi Pekerti.

\section{PENUTUP}

Berdasarkan hasil analisis disimpulkan bahwa penerapan model pembelajaran catur pariksa ternyata dapat meningkatkan aktivitas dan prestasi belajar siswa kelas XI IPB 4 SMA Karya Wisata Singaraja. Hasil penelitian ini dapat diimplementasikan oleh para guru khususnya guru bidang studi pendidikan Agama Hindu dan Budi Pekerti untuk meningkatkan kualitas lulusan siswa.

\section{DAFTAR PUSTAKA}

Abdurahman, Bintoro. 2000. Pendidikan Bagi Anak Berkesulitan Belajar: Jakarta Rineka Cipta.

Abimanyu. Soli. 2008. Strategi Pembelajaran 3 SKS. Direktoral Jendral Pendidikan Tinggi Departemen Pendidikan Nasional. Jakarta.

Dannahauer, Karya J. 2011. Teori Hermeneutika. http://sofyanefendi. wordpress.com

Depdiknas. 2003. Undang-Undang Republik Indonesia No 20 Tahun 2003

Tentang Sitem Pendidikan Nasional. Jakarta: Boro Hukum dan Organisasi

Depdiknas. 2001. Kamus Besar Bahasa Indonesia. Jakarta : Balai Pustaka.

Djmarah Syaiful Bahri.2000. Pendekatan Belajar Mengajar. Jakarta; Rineka Cita.

Dimiati, dan Moedjono . 1994. Setrategi Belajar Mengajar. Angkasa: Bandung.

Hamalik, Oemar. 1990. Psikologi Belajar dan mengajar, bandung: Sinar baru algensindo

Nana Sudjana. 2001. Penilaian Hasil Proses Belajar Menajar. Bandung : PT. Remaja Rosdakarya. 
Nawani. 1984. Pengertian Prestasi Belajar Dari Hasil Belajar. http:// www.wawasanpendidikan.com/pengertian-prestasi-belajar-paraahli.

Palmer Richard E. 2005. Interpratation Theory in Schleirmacher, Dilthey, Heidagger, and Gadamer, Ter. Mansur Hery \& Damanhuri M, Hermeneutika, Teori Baru Mengenai Interprestasi. Yogyakarta: pustaka belajar

Purwanto, Ngalim. 1996. Psikologi Pendidikan. Bandung: Remaja Rosda Karya Sandiyasa. 2014. Pengertin Catur Pariksa dalam Agama Hindu. http: //www. ajaranhindu.com

Ratna Wilis Dahar.1991. Teori-teori Belajar dan Pembelajaran. Bandung: Erlangga.

Sardiman, A.M, dkk. 2007. Interaksi dan Motivasi Belajar Mengajar. Jakarta: PT. Raja Grafindo Persada.

Thorndike, EL. 1999. Teori Behavioristik. Bogor: Rineka Cipta 